\title{
Influence of the Inner and Outer Secondary Air Ratios on the Combustion Characteristic and Flame Shape of a Swirl Burner with a Prechamber
}

\author{
Pengzhong Liu, ${ }^{1,2}$ Fang Niu $\mathbb{D}^{\mathbb{D}},{ }^{2}$ Xuewen Wang, ${ }^{1,2}$ Fei Guo, ${ }^{2}$ Wei Luo, ${ }^{2}$ and Naiji Wang ${ }^{2}$ \\ ${ }^{1}$ China Coal Research Institute, Beijing 100013, China \\ ${ }^{2}$ China Coal Research Institute Company of Energy Conservation, Beijing 100013, China
}

Correspondence should be addressed to Fang Niu; nf37@163.com

Received 22 February 2020; Revised 30 May 2020; Accepted 15 June 2020; Published 24 July 2020

Guest Editor: Yanqing Niu

Copyright ( $\odot 2020$ Pengzhong Liu et al. This is an open access article distributed under the Creative Commons Attribution License, which permits unrestricted use, distribution, and reproduction in any medium, provided the original work is properly cited.

\begin{abstract}
The swirl burner with a prechamber was used in a $14 \mathrm{MW}$ pulverized-coal combustion experiment to investigate the influence of inner and secondary air ratios (ISA/OSA) on the combustion characteristic and flame shape in this work. The temperatures and species concentrations in the prechamber were measured via the flue gas analyzer and thermocouples. The flame shape beyond the prechamber outlet was captured by using a high-speed camera. The results showed that the combustion efficiency was increased and low nitrogen combustion was achieved by adopting the swirl burner with a prechamber. The high temperature corrosion and slagging phenomenon did not occur in the prechamber. The influence of ISA/OSA on temperature and species concentration profiles at different areas in the prechamber was different. The flame shape size exhibited an inflection point with increasing ISA/ OSA. Considering, comprehensively, the temperature peak, near wall temperature, oxygen-free zone, CO concentration, flame length, flame diameter, and divergence angle, the case of ISA/OSA $=1: 2$ had great processing on combustion efficiency and $\mathrm{NO}_{x}$ emission. Thus, ISA/OSA $=1: 2$ was selected as the optimized case under experiment conditions.
\end{abstract}

\section{Introduction}

Pulverized-coal (PC) combustion is one of the maximum coal application approaches. Combustion efficiency and pollutant emissions are the two key factors that restrict the development of PC combustion technology. In order to improve the economic efficiency and ease the pressure on environmental protection, large low nitrogen and high effective combustion technologies [1-5] are developed, such as air staging, fuel staging, flue gas recirculation, fuel rich/lean combustion, and preheating combustion. Achieving these technologies usually depended on the burner or furnace. For the swirl burner, the inner recirculation zone can be formed to keep combustion stable, which is generally applied to the PC boiler. Combining with the abovementioned technologies, the swirl burner has the ability of improving the combustion efficiency and achieving low nitrogen combustion. Flow characteristic analysis is a significant approach to understand and optimize the combustion characteristic of a swirl burner. Li et al. [6] experimentally investigated the gas-particle flow characteristic of an axial swirl burner (LNASB). The air field, gas-particle flow and combustion characteristic of the swirl burner (CFR) were researched by Chen et al. [7, 8]. Also, Zhou et al. [9] numerically analyzed that flame stability and the $\mathrm{NO}_{\mathrm{x}}$ formation mechanism depend on the flow and combustion characteristic of the swirl burner (HT-NR3). Thus, the influences of the swirl burner different variable (such as operating conditions and burner structure) on PC combustion were investigated by the flow and combustion characteristic. For all swirl burners without an adjustable structure, operating conditions [10-15] had significantly impacted on the flow and combustion characteristic. On the influence of the ISA or OSA ratio, Liu et al. [16] researched the position and size of the recirculation zone for LNASB, and the combustion characteristic was discussed in a $600 \mathrm{MW}$ supercritical boiler; some dissertations [17-19] in china, respectively, studied the air flow and combustion characteristic for the CFR swirl 
burner, and Jing et al. [13] discussed the gas-particle flow characteristic. Xue et al. [14] investigated carbon burnout and $\mathrm{NO}_{\mathrm{x}}$ emission with different experimental coals for a radially biased swirl burner. Jiang et al. [20] experimentally researched how to avoid high temperature corrosion by ISA opening of a swirl burner in an opposed wall fired ultrasupercritical boiler. The abovementioned literatures indicated that the relationship between ISA and OSA of a swirl burner had a significant influence on PC combustion.

The swirl burner with a prechamber structure was used to solve the combustion difficult problem on inferior coal by enhancing the recirculation zone and particle concentration. With developing stable combustion technologies [21, 22] and high temperature corrosion and slagging occurring frequently, application of the prechamber structure gradually decreased. At present, a swirl burner with a prechamber appeared in an industrial boiler combining with low nitrogen combustion technologies. Jiang et al. [23] numerically investigated the combustion characteristic of the swirl burner with a double-cone prechamber in an industrial boiler; combining with deep air staging, Wang et al. [24] discussed the $\mathrm{NO}_{\mathrm{x}}$ emission of an industrial boiler. Chi et al. [25] also studied the combustion characteristic of a swirl burner with a prechamber. However, the influence of the ratio of ISA and OSA (ISA/OSA) on the flow and combustion characteristic for a swirl burner with a prechamber was less researched. Gong et al. [26] researched the influence of ISA/OSA for a swirl burner with a prechamber, but ISA and OSA were not provided at the same burner outlet.

In our present work, the influence of ISA/OSA had been investigated on the air flow and combustion characteristic for a swirl burner with a prechamber, but the primary air and PC was reverse flow in the prechamber. Therefore, we decided to experimentally research the influence of ISA/OSA on the combustion and flame characteristic for a swirl burner with a prechamber, in which primary air and PC were normal flow.

\section{Experiment and Methods}

The $14 \mathrm{MW}$ pilot scale PC combustion experiment system was built in our work. Combining with measurement devices and methods, the data of temperature and species concentration in the prechamber and flame shape beyond the prechamber outlet were obtained to analyse the influence of ISA/OSA.

\subsection{Pulverized-Coal Combustion Experiment System.} Figure 1 shows the schematic diagram of the experiment system, which consisted of the coal feeding system, wind system, ignition system, control system, a swirl burner, temperature and gas species concentrations measurements system, and flame capture system. The coal feeding system included storage facilities and feeding devices, and the feeding speed was adjusted by frequency of feeding devices. During each experiment condition, three times of $10 \mathrm{~min}$ feeding speed calibration were carried out, and the error was maintained within $\pm 8 \%$. A Roots fan and three blowers

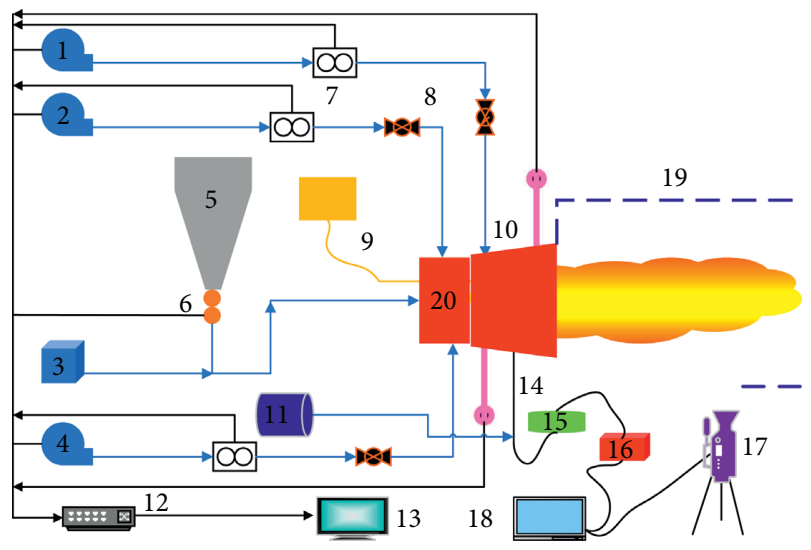

FIGURE 1: Schematic diagram of the experiment system. 1, 2, and 4blower; 3-Roots fan; 5- storage facilities; 6-feeding device; 7- mass flowmeter; 8-valve; 9- ignition device; 10- thermocouple; 11- air compressor; 12- signal exchanger; 13- desktop computer; 14sampling device; 15- filter unit; 16- flue gas analyzer 17- high-speed camera; 18- notebook computer; 19- protective wall; and 20burner.

provide PA (primary air), ISA, OSA, and TA (tertiary air), respectively. Then, the valve was adjusted to control the flow rate displayed by the mass flowmeter. The fuel oil for the ignition system was ignited first, then the PC was fed to achieve stable combustion, and finally, the fuel oil stopped being supplied. The control system was responsible for the start and stop of the whole experiment system. The schematic diagram of the swirl burner is shown in Figure 2, which had 9 axial movable swirl vanes in ISA, an expanding cone-shaped prechamber, a combustion stabilizing device, and an isolated area of PA and OSA.

2.2. Experiment Methods and Conditions. The temperature and gas species concentrations measurements system and the flame capture system in Figure 1 were introduced as measurement methods. The $1.5 \mathrm{~m}$ long stainless steel K-type thermocouple with its own signal converter was adopted to realize the online display of temperature. The measurement range of the thermocouple was $0-1300^{\circ} \mathrm{C}$ with an error of $0.5 \%$. After the temperature was stable, the fluctuation range of $\pm 10^{\circ} \mathrm{C}$ was recorded as the measurement value. Flue gas was sampled by using a water-cooled sucking probe, which consisted of a centrally-located sampling pipe surrounded by a double-deck stainless steel tube with high pressure water for probe cooling. After being quickly cooled by water, gas samples through the unit and were filtered and, then, analyzed online by using a MRU VARIO PLUS flue gas analyzer to obtain the gas species concentrations, with an accuracy consisting of $\pm 2 \%$ for the measurement values of $\mathrm{O}_{2}$ and CO. Sixty groups' data were measured at each measuring point for $120 \mathrm{~s}$, and the mean value of $30 \mathrm{~s}$ stability data was selected as the flue gas species concentration value of this point. The flame capture system mainly meant the high-speed camera, which used its supporting application software (PCC 3.1) to select camera parameters such as a resolution of $1080 \times 504$, exposure time of $200 \mu \mathrm{s}$, and 


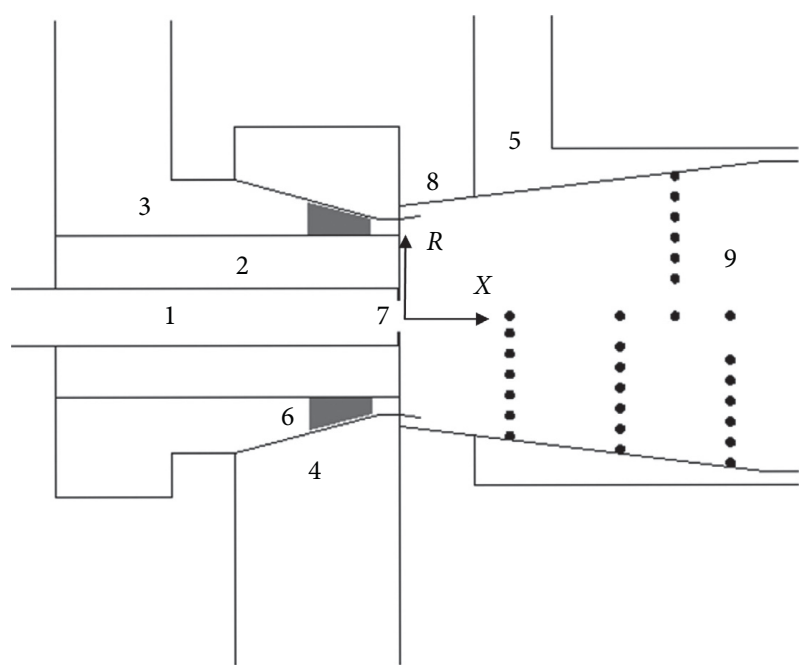

Figure 2: Schematic diagram of the swirl burner with the prechamber. 1-primary air duct; 2-isolate duct; 3-inner secondary air duct; 4-outer secondary air duct; 5-tertiary air duct; 6-axial movable swirl vanes; 7 -combustion stabilizing device; 8-expanding cone-shaped prechamber; 9-location of measuring points.

sampling rate of $1700 \mathrm{fps}$ etc. The scale was arranged at the same section with the burner axis, the high-speed camera took 8337 pictures of the flame, and the picture of the best flame stability and length was selected as the follow-up picture.

In this combustion experiment, Shenfu long flame coal in China was used as the experimental coal, and its basic characteristics are shown in Table 1. As a kind of high volatile coal, it could ensure the smooth ignition and stable combustion for the process of experiment. To avoid the problem of high temperature corrosion and slagging and the flame biasing of the swirl burner horizontal arrangement, wall and swirl wind should be controlled. Considering the flow type difference of ISA and OSA, three experimental cases (ISA/OSA $=2: 1,1: 1,1: 2$ ) were chosen, and the main flow gradually changed from ISA to OSA. The ISA swirl number $(S)$ in Table 2 was calculated using following formula [10]:

$$
S=\frac{2}{3} \times\left[\frac{1-\left(d_{i} / d_{o}\right)^{3}}{1-\left(d_{i} / d_{o}\right)^{2}}\right] \times \tan (\theta),
$$

where $d_{i}$ is the inner diameter of the ISA duct, $d_{o}$ is the outer diameter of the ISA duct, and $\theta$ is the special swirl vane angle in experimental conditions. The other specific experiment parameters such as air mass flow and speed are shown in Table 2.

The axial distance of the burner outlet section and the radial distance of the central axis were defined as $X$ and $R$, respectively. Four sections $X=268,536,670$, and $804 \mathrm{~mm}$ from the measurement position of the burner outlet were selected. The measurement points of each section were, respectively, 10, 60,110,160, 210, and $260 \mathrm{~mm}$ from the wall surface of the prechamber, and the last point was the central axis. Finally, the temperature and flue gas species concentrations, respectively, were measured.
TABLE 1: The basic characteristics of experimental coal.

\begin{tabular}{lc}
\hline Proximate analysis (as received $w t \%, a d)$ & \\
Volatiles & 33.60 \\
Ash & 7.02 \\
Moisture & 5.62 \\
Fixed carbon & 53.76 \\
Net heating value $(\mathrm{kJ} / \mathrm{kg}$ ) & 27200 \\
\hline Ultimate analysis (as received $w t \%, a d)$ & \\
Carbon & 61.54 \\
Hydrogen & 4.16 \\
Oxygen & 11.64 \\
Nitrogen & 0.82 \\
Sulfur & 0.43 \\
\hline
\end{tabular}

TABLE 2: Experimental conditions and parameters.

\begin{tabular}{lccc}
\hline ISA/OSA & $2: 1$ & $1: 1$ & $1: 2$ \\
Feeding speed $(\mathrm{kg} / \mathrm{h})$ & 1140 & 1140 & 1140 \\
Primary air $(\mathrm{kg} / \mathrm{h})$ & 900 & 900 & 900 \\
Primary air speed $(\mathrm{m} / \mathrm{s})$ & 26.3 & 26.3 & 26.3 \\
Inner secondary air $(\mathrm{kg} / \mathrm{h})$ & 3889 & 2917 & 1945 \\
Inner secondary air speed $(\mathrm{m} / \mathrm{s})$ & 22.3 & 16.7 & 11.1 \\
ISA swirl number $(S)$ & 1.6 & 1.6 & 1.6 \\
Outer secondary air $(\mathrm{kg} / \mathrm{h})$ & 1945 & 2917 & 3889 \\
Outer secondary air speed $(\mathrm{m} / \mathrm{s})$ & 14.0 & 21.0 & 28.0 \\
Tertiary air $(\mathrm{kg} / \mathrm{h})$ & 1955 & 1955 & 1955 \\
Tertiary air speed $(\mathrm{m} / \mathrm{s})$ & 4.5 & 4.5 & 4.5 \\
All air temperature $\left({ }^{\circ} \mathrm{C}\right)$ & 20 & 20 & 20 \\
\hline
\end{tabular}

\section{Results and Discussion}

The experimental results were obtained and divided into three parts to discuss the influence of ISA/OSA, and then, the specific process is as follows.

3.1. Effect of the ISA/OSA for Temperature in the Prechamber. Figure 3 shows different temperature profiles in the prechamber with different ISA/OSA. (a), (b), (c), and (d) in Figure 3 are $X=268 \mathrm{~mm}, 536 \mathrm{~mm}, 670 \mathrm{~mm}$, and $804 \mathrm{~mm}$, respectively. For all the cross sections of ISA/OSA in the radial direction, the high temperature zone could be seen in different areas of each temperature profile. This finding demonstrated that sufficient combustion of PC depended on ISA in the prechamber. OSA was used to decrease wall temperature and rich fuel combustion appeared on the central axis. $T_{\mathrm{p}}$ (peak temperature) $=933^{\circ} \mathrm{C}$ appeared at $R=191 \mathrm{~mm}$ for ISA/OSA $=2: 1$ was lower and farther away from the central axis than other cases in the high-temperature zone, Figure 3(a). The divergence ability of strong swirl was the main reason. Another $T_{p}$ found was $1015^{\circ} \mathrm{C}$ at $R=41 \mathrm{~mm}$, indicating that PC ignited and burned near the central axis. The temperature for ISA/OSA $=2: 1$ was higher than others in the area near the wall $(R>191 \mathrm{~mm})$, indicating that the function of ISA was to ensure complete combustion. Figures 3(b) and 3(c) are same as 3(a). In Figure $3(d), T_{p}$ appeared at the same position, and the difference of vales was slight. The temperature for ISA/ OSA $=1: 1$ was higher than that of others at the 


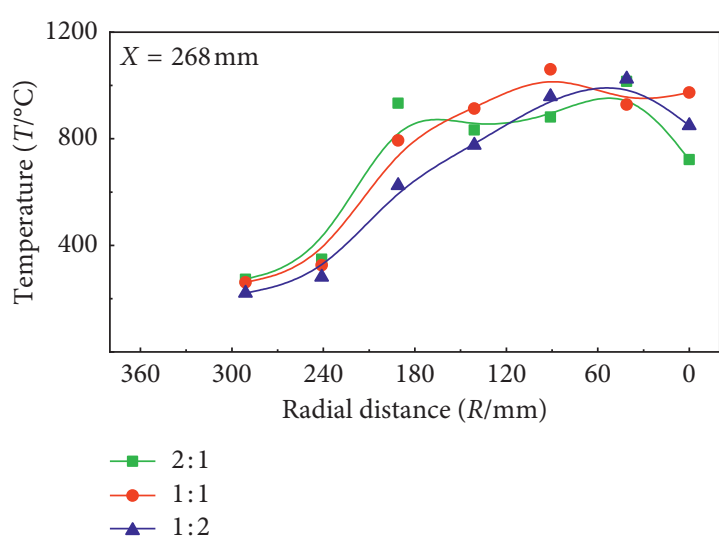

(a)

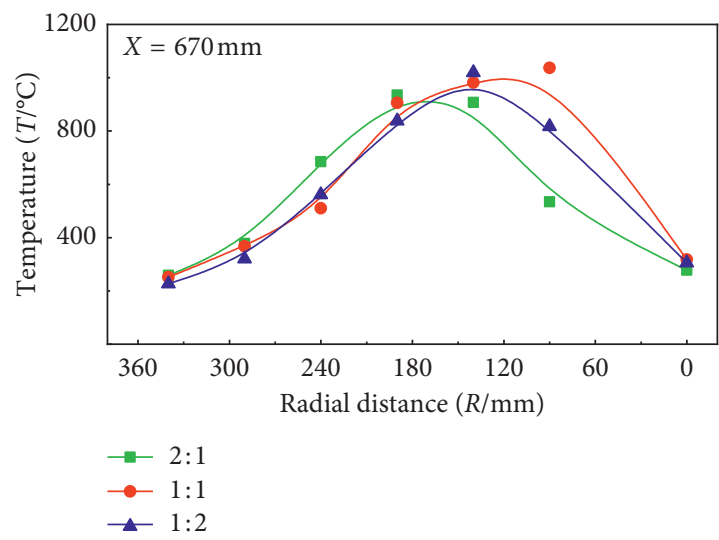

(c)

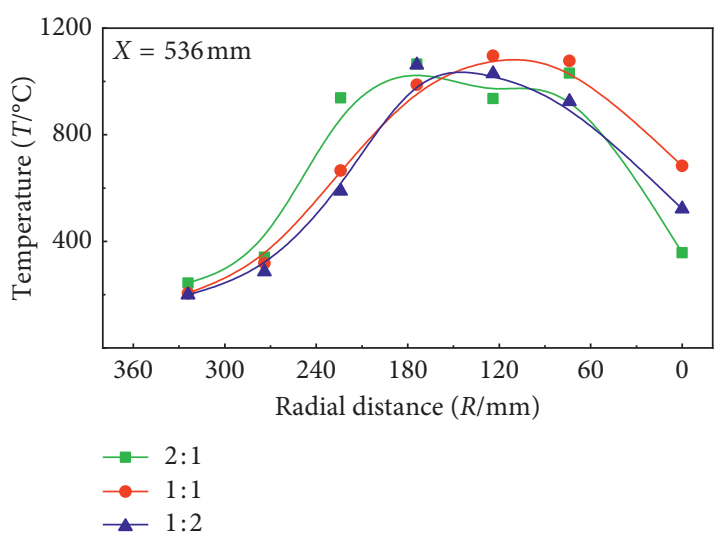

(b)

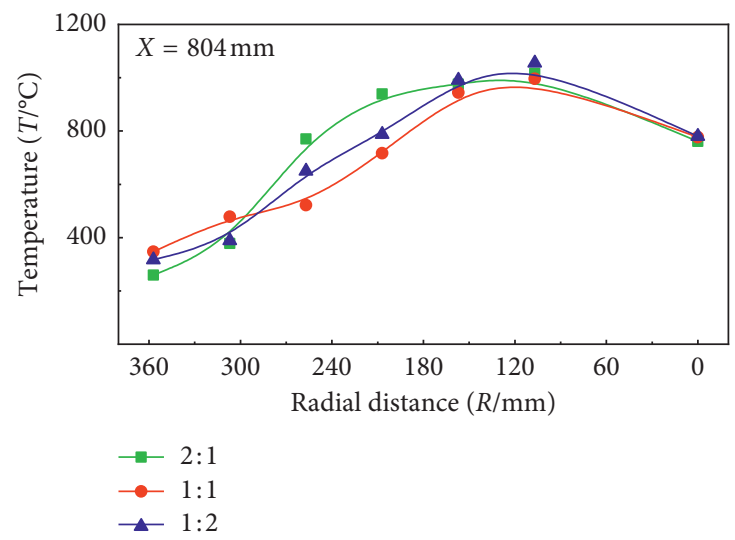

(d)

Figure 3: Temperature profiles along radial distance for different ISA/OSA. (a) $X=268 \mathrm{~mm}$. (b) $X=536 \mathrm{~mm}$. (c) $X=670 \mathrm{~mm}$. (d) $X=804 \mathrm{~mm}$.

$R=307-357 \mathrm{~mm}$ area, indicating that the ISA or OSA remaining mainstream position helped to reduce wall temperature of the prechamber downstream.

Figure 4 shows the temperature profiles of the central axis (Figure 4(a)) and the wall position in the prechamber (Figure 4(b)) with different ISA/OSA. Along axis distance, the low-temperature zone could be seen for all ISA/OSA in Figure 4(a). The reason was that the mixing of ISA decayed and the endothermic process of PC pyrolysis appeared. Comparing different ISA/OSA, the temperature for ISA/ OSA $=2: 1$ was lower than that of others. It was indicated that $T_{\mathrm{p}}$ was lower and farther at the same PA and PC feeding speed. In Figure 4(b), the distance from the measurement point to the prechamber inner wall was $10 \mathrm{~mm}$, and temperatures for all ISA/OSA were lower than $400^{\circ} \mathrm{C}$. It was indicated that high temperature corrosion could be avoided, and the prechamber adopted general steel material. The results showed that OSA designed had a cooling effect in the prechamber. Besides the $X=804 \mathrm{~mm}$ point, temperature for ISA/OSA = 1:2 was lower than that of others, indicating that increasing OSA enhanced the cooling effect.

For the swirl burner with a prechamber, the function of PA, ISA, and OSA, respectively, was ignition, ensuring stable combustion and decreasing temperature in the prechamber. Also, the endothermic process of PC pyrolysis appeared, and high-temperature corrosion was avoided. The influence of ISA/OSA on different position temperature in the prechamber was significant.

\subsection{Effect of the ISA/OSA for Flue Gas Species Concentrations} in the Prechamber. The $\mathrm{O}_{2}$ and $\mathrm{CO}$ concentration profiles with different ISA/OSA are shown in Figures 5 and 6, respectively. The $\mathrm{O}_{2}$ concentration increased from near $0 \%$ to near $21 \%$, and the CO concentration decreased from high concentration to near $0 \mathrm{ppm}$ along radial direction for different ISA/OSA at all cross sections. The oxygen-free and high $\mathrm{CO}$ concentration zone $\left(\mathrm{O}_{2}<1 \%, \mathrm{CO}>5 \times 10^{4} \mathrm{ppm}\right)$ could be found in the prechamber. It could be attributed to $\mathrm{PC}$ incomplete combustion and species diffusion.

For the case of ISA/OSA $=2: 1$, the $\mathrm{O}_{2}$ concentration $(R>120 \mathrm{~mm})$ and oxygen-free zone, respectively, were higher and smaller than others, and the CO concentration was lower first and higher than others, as shown in Figures 5(a), 5(b), 6(a), and 6(b). The reason was that the divergence ability of strong swirl inhibited species diffusion. In Figures 5(c) and 6(c), the difference of $\mathrm{O}_{2}$ concentration profiles for three ISA/OSA was not obvious besides $R=90-140 \mathrm{~mm}$, and CO concentration for ISA/OSA $=1: 2$ was slightly higher than others besides the central axis point. 


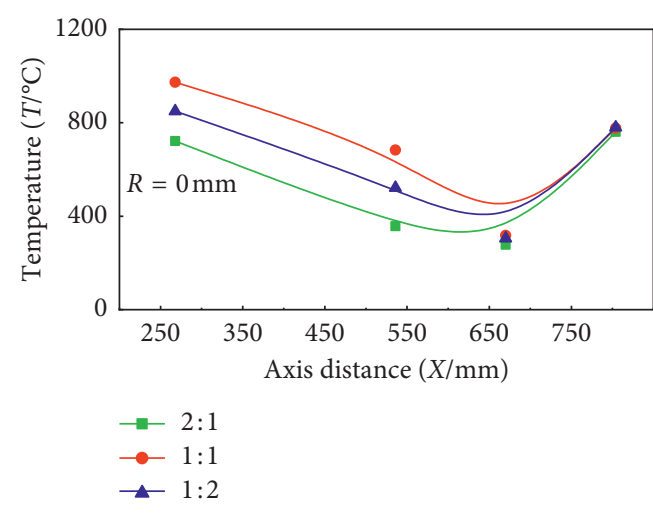

(a)

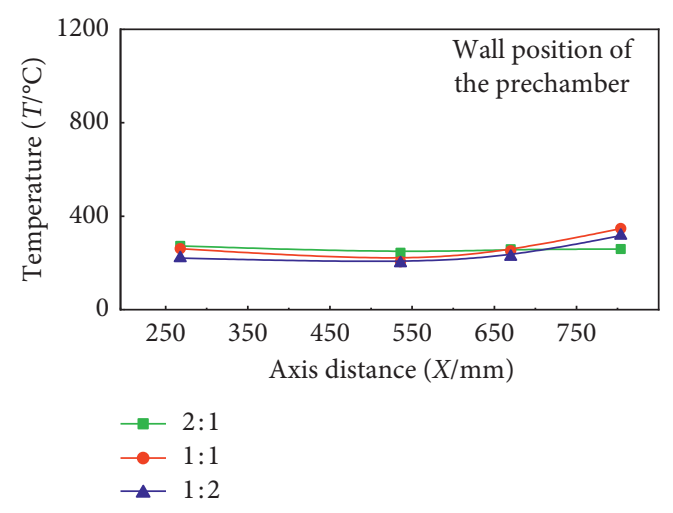

(b)

FIGURE 4: Temperature profiles along axis distance for different ISA/OSA.

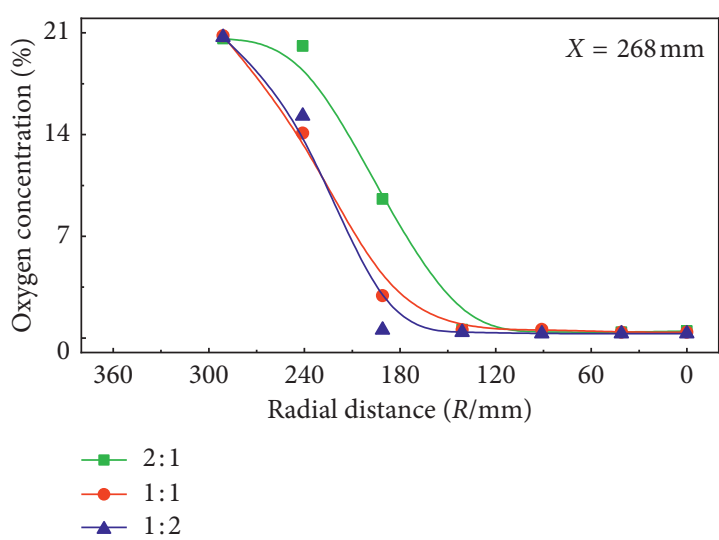

(a)

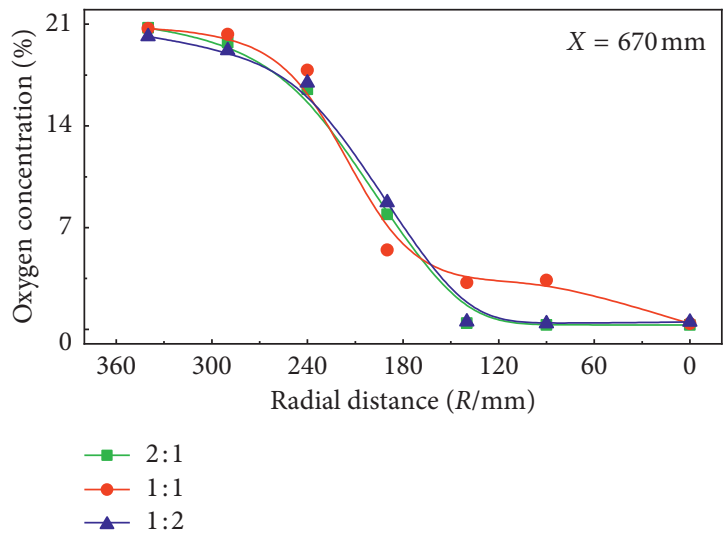

(c)

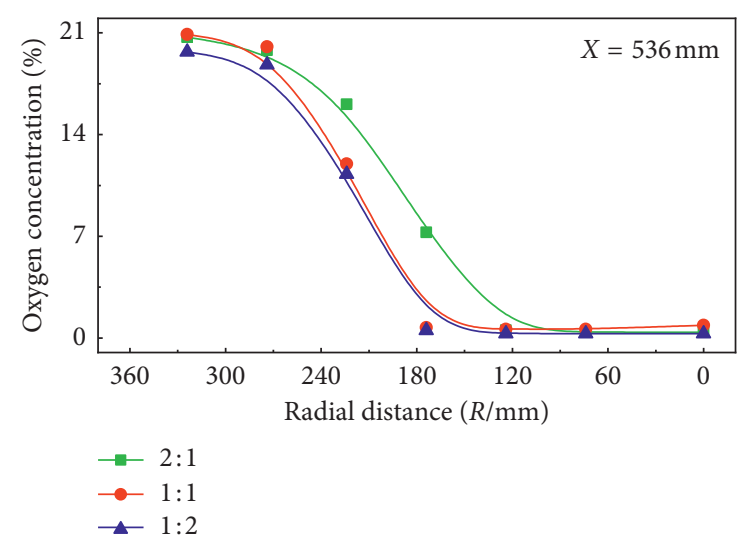

(b)

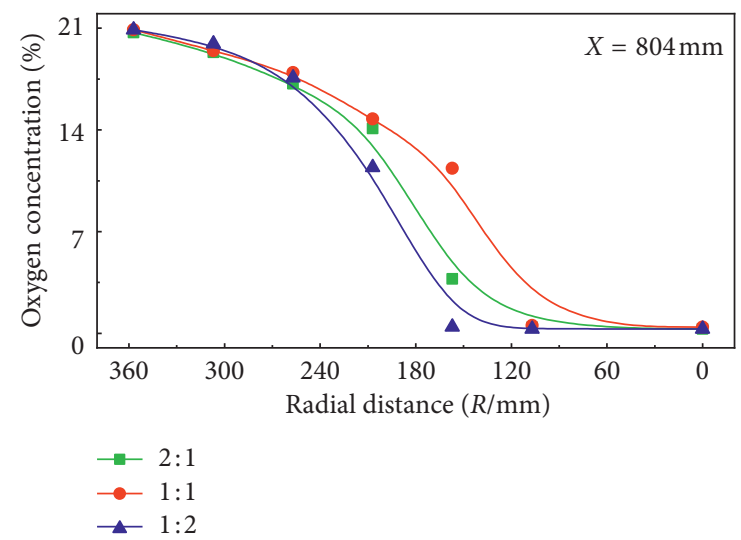

(d)

FIgURE 5: $\mathrm{O}_{2}$ concentration profiles along radial distance for different ISA/OSA. (a) $X=268 \mathrm{~mm}$. (b) $X=536 \mathrm{~mm}$. (c) $X=670 \mathrm{~mm}$. (d) $X=804 \mathrm{~mm}$.

It was indicated that ISA and OSA gradually mixed. In Figures 5(d) and 6(d), the oxygen-free zone and $\mathrm{O}_{2}$ concentration $(R>120 \mathrm{~mm})$, respectively, were bigger and lower than others, and the CO concentration was higher than others for ISA/OSA $=1: 2$. The reason was that the mixing of PA and SA was weak, under the diversity of ISA and OSA was larger condition.
Figures 7 and 8 showed the $\mathrm{O}_{2}$ and $\mathrm{CO}$ concentration profiles of the central axis (Figures 7(a) and 8(a)) and the wall position of the prechamber (Figures $7(b)$ and $8(b)$ ) for three ISA/OSA. There were oxygen-free and high CO concentration on the central axis with different ISA/OSA. The CO concentration for ISA/OSA $=2: 1$ was higher than that of others, indicating that pyrolysis processing was 


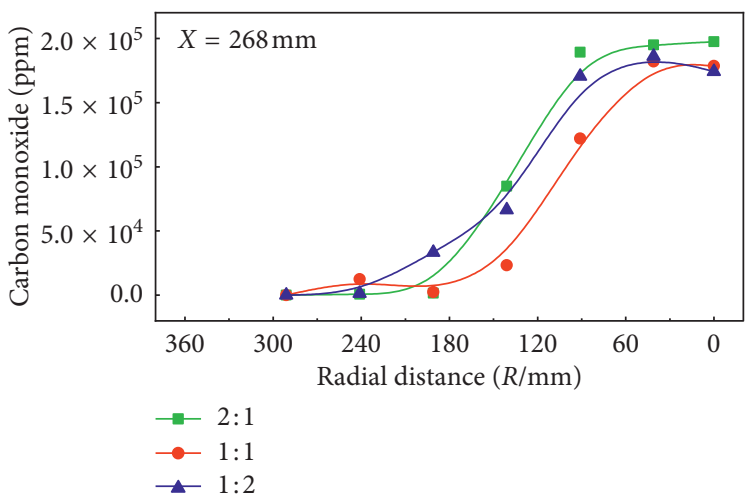

(a)

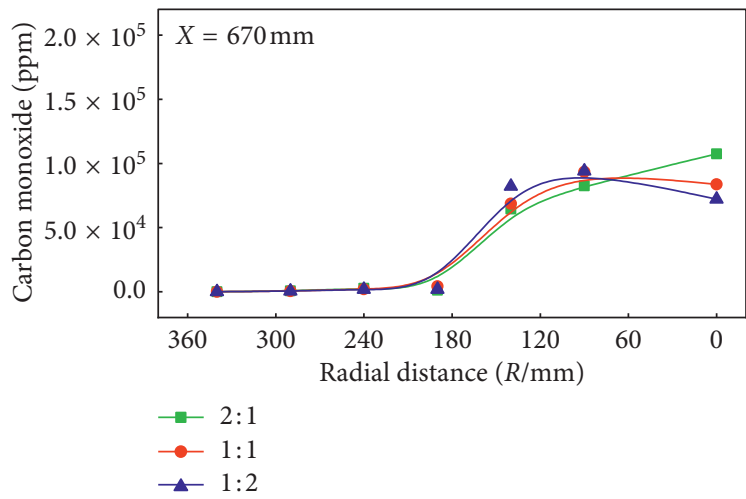

(c)

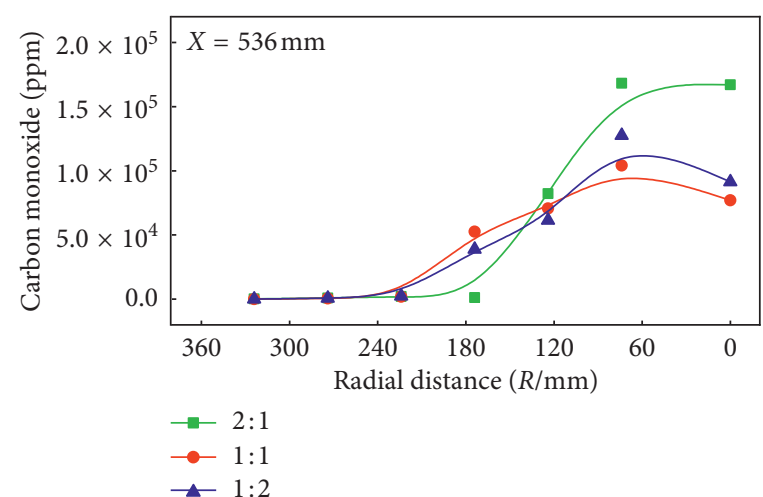

(b)

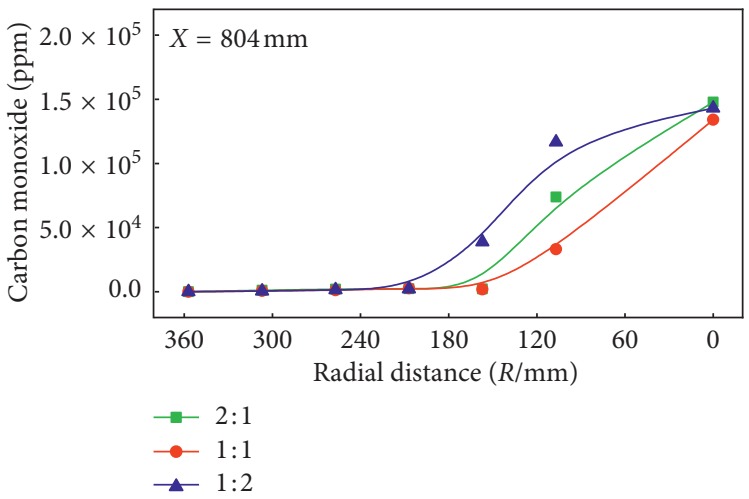

(d)

Figure 6: CO concentration profiles along radial distance for different ISA/OSA. (a) $X=268 \mathrm{~mm}$. (b) $X=536 \mathrm{~mm}$. (c) $X=670 \mathrm{~mm}$. (d) $X=804 \mathrm{~mm}$.

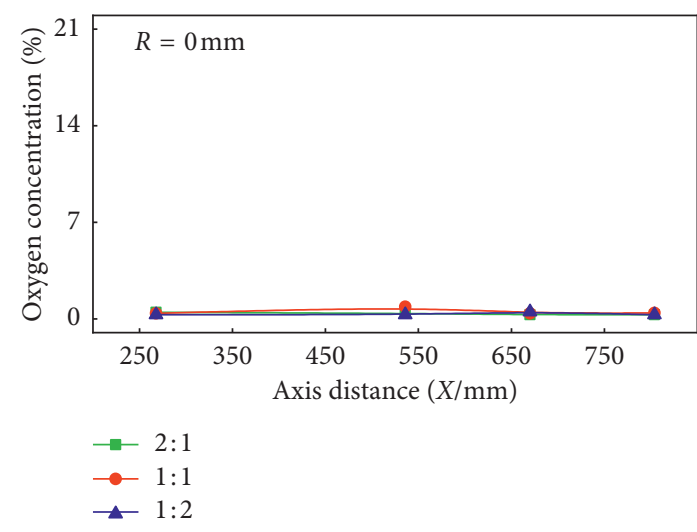

(a)

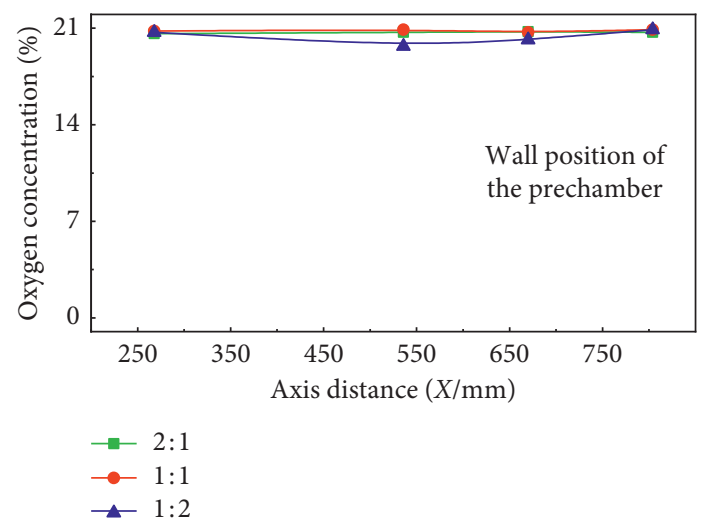

(b)

FIgURE 7: $\mathrm{O}_{2}$ concentration profiles along axis distance for different ISA/OSA.

strong to decrease temperature. At the side wall of the prechamber, the $\mathrm{O}_{2}$ concentration and $\mathrm{CO}$ concentration were close to $21 \%$ and $0 \mathrm{ppm}$ with different ISA/OSA, indicating that the cooling effect of ISA was evidenced. Also, the high temperature corrosion and slagging could be avoided.

In the prechamber of the swirl burner, the zone of oxygen-free and high $\mathrm{CO}$ concentration was found on the centre. The results showed that strong reducing atmosphere inhibited $\mathrm{NO}_{\mathrm{x}}$ generation and decreased $\mathrm{NO}_{\mathrm{x}}$ emission. ISA/ OSA had impacted on no oxygen boundary and CO concentration of different regions. The high temperature corrosion and slagging phenomenon did not occur.

3.3. Effect of the ISA/OSA for a Flame Shape beyond the Prechamber Outlet. Figure 9 shows different flame shapes and profiles for different ISA/OSA. All images in Figure 9 


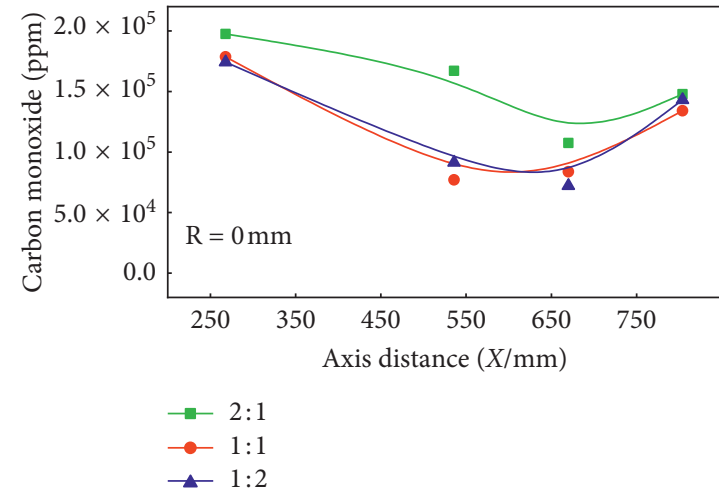

(a)

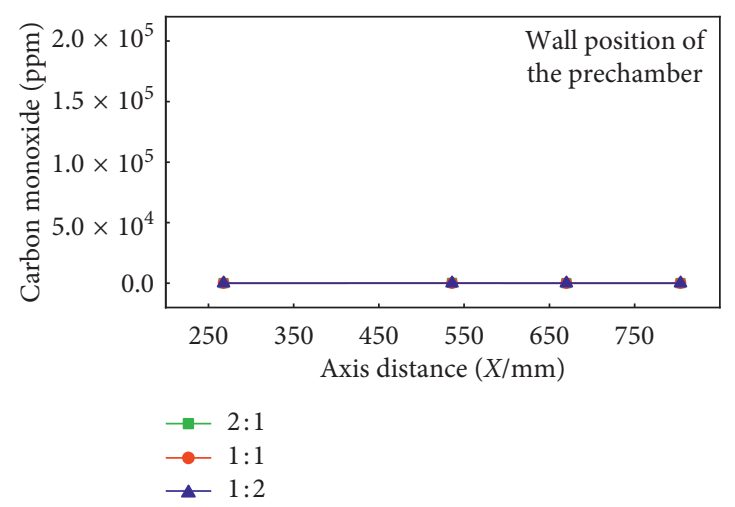

(b)

FIGURE 8: CO concentration profiles along axis distance for different ISA/OSA.
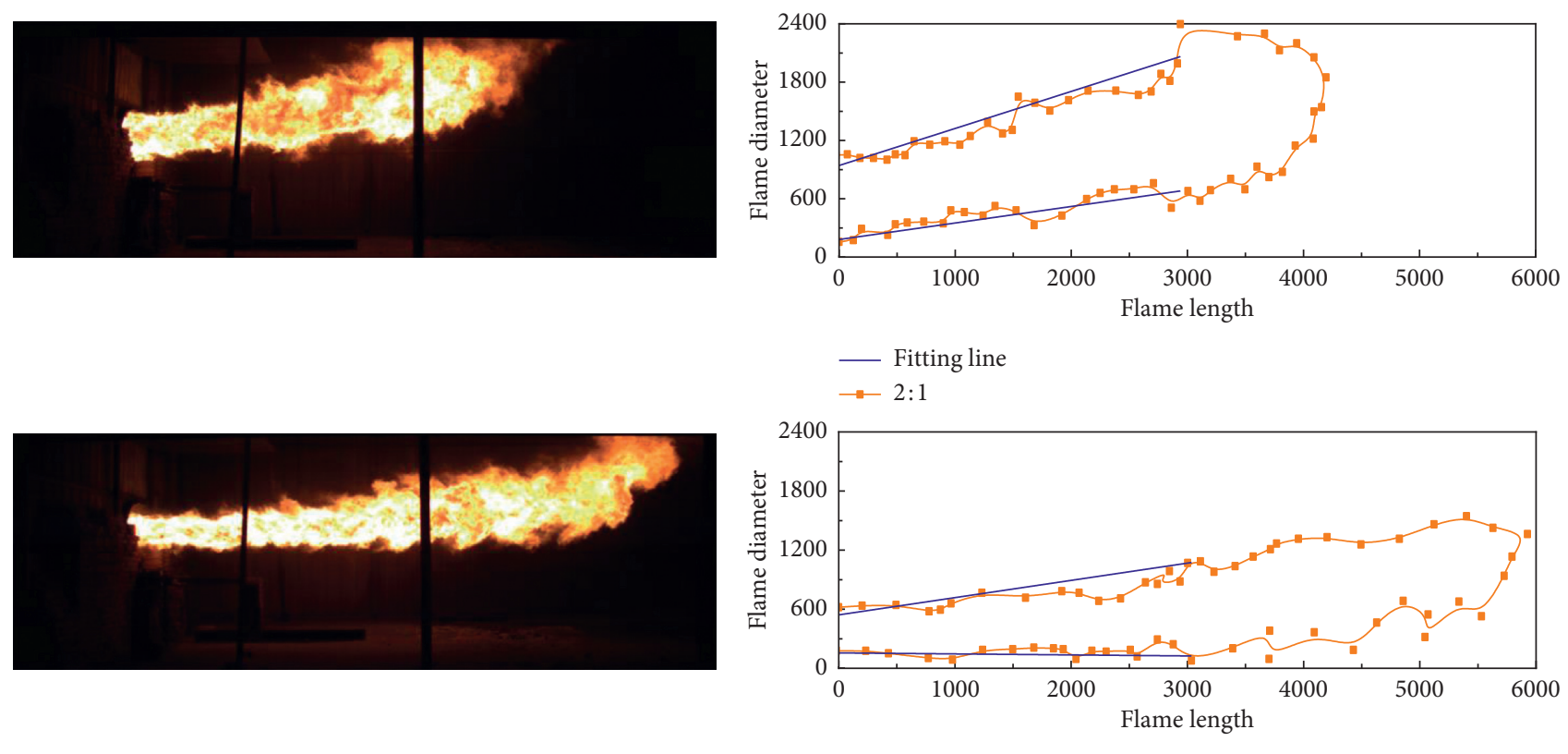

_ Fitting line

$\rightarrow 1: 1$
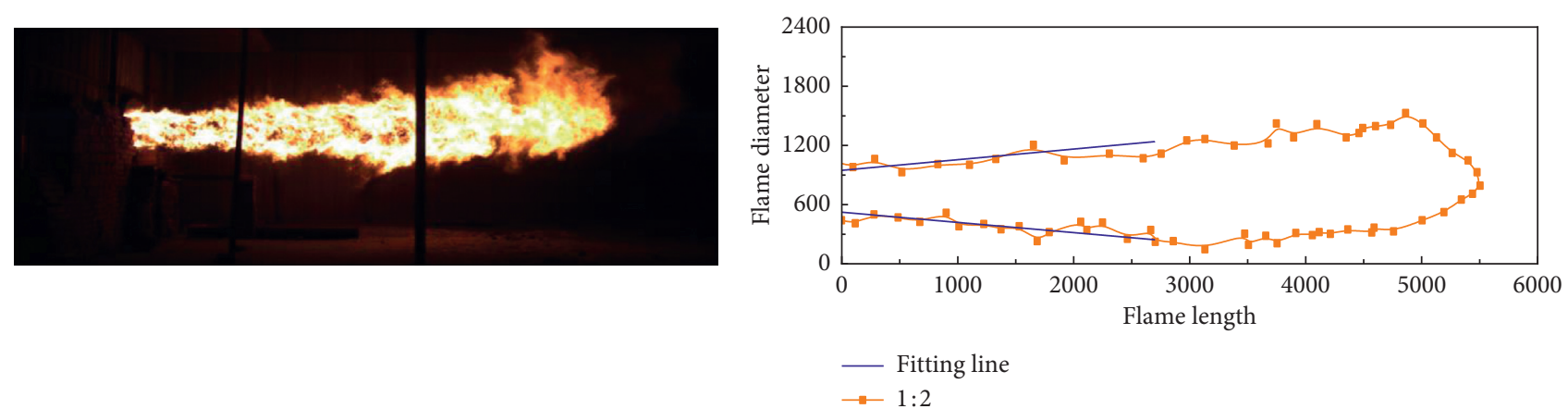

(a)

(b)

FIGURE 9: Flame shapes and profiles for different ISA/OSA.

showed that the flame surface had a typical turbulence structure, which was favorable for mass, heat diffusion, and flame propagation beyond the prechamber outlet. This indicated that the prechamber had the advantages in enhancing flame stability when it was adopted in the swirl burner. Also, the interaction with external air flow indicates 
Table 3: Flame shapes size for different ISA/OSA.

\begin{tabular}{lccccccc}
\hline \multirow{2}{*}{ ISA/OSA } & $\begin{array}{c}\text { Upper flame surface } \\
\text { Intercept }(\mathrm{mm})\end{array}$ & $\begin{array}{c}\text { Downward flame surface } \\
\text { Slope }\end{array}$ & $\begin{array}{c}\text { Intercept }(\mathrm{mm}) \\
\text { Slope }\end{array}$ & Flame diameter $(\mathrm{mm})$ & Flame divergence angle $\left(^{\circ}\right)$ & Flame length $(\mathrm{mm})$ \\
\hline $2: 1$ & 941.9 & 0.3813 & 179.1 & 0.1670 & 762.8 & 12.1 & 4194 \\
$1: 1$ & 542.4 & 0.1752 & 156.3 & -0.0102 & 386.1 & 10.5 & 5926 \\
$1: 2$ & 947.3 & 0.1079 & 522.5 & -0.1033 & 424.8 & 11.9 & 5504 \\
\hline
\end{tabular}

that it was diffusion flame. Therefore, the flame was judged as a turbulent diffusion structure. A long low-speed flow region was formed to stabilize flame, because high-speed jets and the prechamber structure were used. According to the scale placed on the central axis section of the swirl burner, the flame profiles were drawn to obtain the flame length data beyond the prechamber outlet. At the same time, the slope and intercept of the fitting line were used to obtain the flame diameter and divergence angle data at the prechamber outlet. The specific data are shown in Table 3.

The divergence angle decreased from $12.1^{\circ}$ to $10.5^{\circ}$ at first and, later, rose to $11.9^{\circ}$ with decreasing ISA/OSA. The finding indicated that the flame divergence angle for ISA/ OSA $=1: 1$ was lower than that for others. Also, the flame length was longer than that of others, and the diameter was narrower than that of others. The length value varied from $4194 \mathrm{~mm}$ to $5926 \mathrm{~mm}$ at first and, later, to $5504 \mathrm{~mm}$ with decreasing ISA/OSA, and the diameter varied from $762.8 \mathrm{~mm}$ to $386.1 \mathrm{~mm}$ and to $424.8 \mathrm{~mm}$. The rough and short flame for ISA/OSA $=2: 1$ were caused due to its rotational divergent ability. The flame length was shortened, and the diameter was widened due to the low-speed flow region slight shortening beyond the prechamber outlet.

The gradient of jet velocity along the radial direction was low for ISA/OSA =1:1 which stretched the low-speed flow region of flame stability.

The swirl burner with the prechamber had stable PC combustion flame with different ISA/OSA. An inflection point of flame shape was found, indicating that reasonable ISA/OSA needed to be considered.

Temperatures and species concentrations in the prechamber reflected PC burning out, low nitrogen combustion, corrosion, and slagging. Flame shape beyond the prechamber outlet exhibited a jet characteristic and high temperature zone in the future boiler. Also, the flame shape was affected by the combustion characteristic in the prechamber. Thus, the combustion efficiency and $\mathrm{NO}_{\mathrm{x}}$ emissions were predicted by temperatures, species concentrations, and flame shapes. Combining with the influence of ISA/OSA, reasonable ISA/OSA was selected to the optimize operation condition of the swirl burner with the prechamber.

\section{Conclusions}

The temperatures and flue gas species concentrations in the prechamber and flame shapes beyond the prechamber outlet of the burner were researched and analyzed with variable ISA/OSA, and conclusions were obtained as follows:

(1) The high temperature, the oxygen-free zone, and high CO concentrations were found in the prechamber, and a long stable flame shape was observed beyond the prechamber outlet. It was evidenced that the swirl burner with the prechamber had certain ability of increasing the combustion efficiency and low nitrogen combustion. The high-temperature corrosion and slagging phenomenon of the prechamber were avoided by designing OSA.

(2) The influence of ISA/OSA was reflected on the temperature peak, near wall temperature, oxygenfree boundary, and CO concentrations in the prechamber. In the prechamber upstream, the temperature peak and oxygen-free zone decreased, with increasing ISA/OSA, near wall temperature, and CO concentrations. In the prechamber downstream, the oxygen-free zone increased, with decreasing ISA/ OSA, and CO concentrations increased. The temperature peak had a slight difference.

(3) The influence of ISA/OSA on the flame shape was analyzed by flame length, diameter, and divergence angle. Flame length had a maximum inflection point, with decreasing ISA/OSA, and flame diameter and divergence angle had a minimum inflection point. The relation between flame length and others was a contradiction and needed to consider comprehensively.

(4) According to temperature profiles, species concentrations profiles, and flame shapes size, the ISA/ OSA $=1: 2$ case had higher temperature peak and $\mathrm{CO}$ concentrations, larger oxygen-free zone, and lower near wall temperature. Also, flame length was longer, and flame diameter and divergence angle were larger. Therefore, the ISA/OSA $=1: 2$ experimental condition was selected as a reasonable operating condition, under the experimental coal, $63 \%$ load, and ISA swirl number $S=1.6$ of the swirl burner with a prechamber.

\section{Data Availability}

No data were used to support this study. The burn of the experiment is available from the authors.

\section{Conflicts of Interest}

The authors declare that there are no conflicts of interest regarding the publication of this paper.

\section{Acknowledgments}

This research was financially supported by the Foundation of China Coal Technology Engineering Group (2018TDMS007) and China Coal Research Institute Company of Energy Conservation (2020JNCX01-04). 


\section{References}

[1] W. Fan, Z. Lin, Y. Li, J. Kuang, and M. Zhang, "Effect of airstaging on anthracite combustion and $\mathrm{NO}_{\mathrm{x}}$ Formation," Energy \& Fuels, vol. 23, no. 1, pp. 111-120, 2009.

[2] J. Yang, R. Sun, S. Sun et al., "Experimental study on $\mathrm{NO}_{\mathrm{x}}$ reduction from staging combustion of high volatile pulverized coals. Part 2. Fuel staging," Fuel Processing Technology, vol. 138, pp. 445-454, 2015.

[3] H. K. Kim, Y. Kim, S. M. Lee, and K. Y. Ahn, "NO reduction in 0.03-0.2 MW oxy-fuel combustor using flue gas recirculation technology," Proceedings of the Combustion Institute, vol. 31, no. 2, pp. 3377-3384, 2007.

[4] Z. Li, S. Li, Q. Zhu et al., "Effects of particle concentration variation in the primary air duct on combustion characteristics and $\mathrm{NO}_{\mathrm{x}}$ emissions in a $0.5-\mathrm{MW}$ test facility with pulverized coal swirl burners," Applied Thermal Engineering, vol. 73, no. 1, pp. 859-868, 2014.

[5] Z. Ouyang, J. Zhu, and Q. Lu, "Experimental study on preheating and combustion characteristics of pulverized anthracite coal," Fuel, vol. 113, pp. 122-127, 2013.

[6] Z. Li, L. Zeng, G. Zhao et al., "Cold experimental investigations into gas/particle flow characteristics of a low- $\mathrm{NO}_{\mathrm{x}}$ axial swirl burner in a $600-\mathrm{MWe}$ wall-fired pulverized-coal utility boiler," Experimental Thermal and Fluid Science, vol. 37, pp. 104-112, 2012.

[7] Z. Chen, Z. Li, J. Jing, L. Chen, S. Wu, and Y. Yao, "Study on flow fields of centrally fuel rich swirl burner and its applications," Korean Journal of Chemical Engineering, vol. 26, no. 5, pp. 1186-1193, 2009.

[8] Z. Chen, Z. Li, Q. Zhu, and J. Jing, "Gas/particle flow and combustion characteristics and $\mathrm{NO}_{\mathrm{x}}$ emissions of a new swirl coal burner," Energy, vol. 36, no. 2, pp. 709-723, 2011.

[9] C. Zhou, Y. Wang, Q. Jin, Q. Chen, and Y. Zhou, "Mechanism analysis on the pulverized coal combustion flame stability and $\mathrm{NO}_{\mathrm{x}}$ emission in a swirl burner with deep air staging," Journal of the Energy Institute, vol. 92, no. 2, pp. 298-310, 2019.

[10] Y. Sung and G. Choi, "Effectiveness between swirl intensity and air staging on $\mathrm{NO}_{\mathrm{x}}$ emissions and burnout characteristics in a pulverized coal fired furnace," Fuel Processing Technology, vol. 139, pp. 15-24, 2015.

[11] J. Jing, Z. Li, Q. Zhu, Z. Chen, and F. Ren, "Influence of primary air ratio on flow and combustion characteristics and $\mathrm{NO}_{\mathrm{x}}$ emissions of a new swirl coal burner," Energy, vol. 36, no. 2, pp. 1206-1213, 2011.

[12] S. Li, Z. Li, B. Jiang, Z. Chen, and X. Zhang, "Effect of secondary air mass flow rate on the airflow and combustion characteristics and $\mathrm{NO}_{\mathrm{x}}$ formation of the low-volatile coalfired swirl burner," Asia-Pacific Journal of Chemical Engineering, vol. 10, no. 6, pp. 858-875, 2015.

[13] J. Jing, C. Zhang, W. Sun, J. An, J. Bi, and Z. Li, "Influence of mass-flow ratio of inner to outer secondary air on gas-particle flow near a swirl burner," Particuology, vol. 11, no. 5, pp. 540-548, 2013.

[14] S. Xue, S. Hui, T. Liu, Q. Zhou, T. Xu, and H. Hu, "Experimental investigation on $\mathrm{NO}_{\mathrm{x}}$ emission and carbon burnout from a radially biased pulverized coal whirl burner," Fuel Processing Technology, vol. 90, no. 9, pp. 1142-1147, 2009.

[15] R. Luo, N. Li, Y. Zhang et al., "Effect of the adjustable inner secondary air-flaring angle of swirl burner on coal-opposed combustion," Journal of Energy Engineering, vol. 142, no. 1, Article ID 04015081, 2016.

[16] J. Liu, B. Sun, T. Bai et al., "Numerical simulation and optimization on temperature field of $600 \mathrm{MW}$ supercritical swirl combustion boiler," Proceedings of the CSEE, vol. 31, no. 2, pp. 15-21, 2011.

[17] S. Li, Investigation of Central-Fuel-Richswirling Combustion Technology Withlow-Volatile Coal, Harbin Institute of Technology, Harbin, China, 2016.

[18] Y. Xie, Influence of the Ratio of Inner Secondary Air and Outer Secondary Air on Combustion Characteristics of a Centrally Fuel Rich Swirl Burner, Harbin Institute of Technology, Harbin, China, 2014.

[19] Z. Wang, Influence of the Ratio of Inner Secondary Air and Outer Secondary Air on Combustion Characteristics of a Swirl Burner under Sub-Stoichiometric Ratio, Harbin Institute of Technology, Harbin, China, 2012.

[20] B. Jiang, F. G. Liu, K. Liu, and H. J. Liu, "Experimental research on high temperature corrosion prevention technology for water wall of opposed wall fired ultra supercritical boiler," Applied Mechanics and Materials, vol. 654, pp. 69-73, 2014.

[21] L. Zhao, Q. Zhou, and C. Zhao, "Fourth technology of combustion stability for swirl combustion," Journal of Southeast University (Natural Science Edition), vol. 36, no. 4, pp. 551-555, 2006.

[22] H. Zhou, D.-P. Sun, Q. Fang et al., "Development and prospect of combustion stabilizing technologies of pulverized coal," Journal of Power Engineering, vol. 28, no. 5, pp. 657663,2008

[23] S.-Y. Jiang, Y.-Y. Wang, J.-M. Zhou et al., "Numerical simulation on middle volatile coal combustion in reversed injection burner," Journal of China Coal Society, vol. 39, no. 6, pp. 1147-1153, 2014.

[24] P. Wang, N. Wang, X. Chen et al., "Numerical simulation of deep air-staged technology in pulverized coal industrial boiler," Clean Coal Technology, vol. 24, no. 5, pp. 68-76, 2018.

[25] J. Chi, Z. Chi, G. Sun et al., "Numerical simulation and experimental study of burner and furnace of pulverized coal -fired industrial boiler," Power System Engineering, vol. 29, no. 5, pp. 1-4, 2013.

[26] Y. Gong, X. Xu, D. Wang et al., " $\mathrm{NO}_{\mathrm{x}}$ emission characteristics of a novel low- $\mathrm{NO}_{\mathrm{x}}$ swirl burner," Clean Coal Technology, vol. 25, no. 6, pp. 118-125, 2019. 